\title{
LONG TERM PERFORMANCE PREDICTION FOR DHW SOLAR SYSTEMS BASED ON INPUT-OUTPUT TEST METHOD
}

\author{
B.Bourges $^{+}$, A. Rabl ${ }^{*}$, B.Leide ${ }^{*}$, M.J.Carvalho ${ }^{\#}$, M.Collares-Pereira ${ }^{x}$ \\ + Consultant; 6 rue d'Armor; 35760 St.-Grégoire; France \\ * École des Mines; 60 Boul. St. Michel; 75272 PARIS CEDEX 06; France \\ \# Dept. Ener. Renováveis; LNETI; Paço do Lumiar; 1699 LISBOA CODEX; Portugal \\ x Centro Conservação Energia; R. S. Domingos à Lapa, 117, 1200 LISBOA, Portugal
}

\section{ABSTRACT}

A Long Term Performance Prediction (LTPP) method based on the results obtained with the InputOutput test method for DHW Solar Systems, developed by the Collector and System Testing Group (CSTG,1987), is described. An analyses of the influence of measurement errors in the LTPP is presented.

\section{KEYWORDS}

Long Term Performance Prediction (LTPP); Input-Output (I-O) Test Method; Domestic Hot Water (DHW) Solar System

\section{INTRODUCTION}

The basic decision criteria for the purchase of a solar water heater are the cost of the system and the value of the energy delivered by the system over its lifetime. To determine the latter, a standard test procedure is necessary. This procedure should: i) allow prediction of long term average performance for any set of reasonable operating conditions; ii) have sufficient accuracy to permit a meaningful ranking of candidate systems; and iii) not impose a significant cost burden.

In Europe the Solar Collector and System Testing Group (CSTG, 1987) developed a test procedure for which the system is considered to be a black box with certain input-output parameters. This method is very flexible for extrapolation to different utilization conditions. In this work a LTPP method, based on this test method is presented. A systematic analysis of measurement errors and their consequences for the uncertainty of the LTPP can be found in (B.Bourges et al.,1989) and will be summarized here.

\section{TEST PROCEDURE}

The CSTG test procedure is based on the linear Input-Output model for the daily performance of solar water heaters. According to this model the heat $\mathrm{Q}$ [in $\mathrm{MJ}$ ] added to the tank during the day is a simple linear function

of three variables,

$$
\mathrm{Q}=\alpha_{\mathrm{o}}+\alpha_{\mathrm{H}} \mathrm{H}+\alpha_{\mathrm{T}} \mathrm{T} \text { with } \mathrm{T}=\left(\mathrm{T}_{\mathrm{a}}-\mathrm{T}_{\mathrm{s}}\right)
$$


$\mathrm{H}=$ daily total solar irradiation on collector aperture $\left[\mathrm{MJ} / \mathrm{m}^{2}\right]$,

$\mathrm{T}_{\mathbf{a}}=$ daytime average ambient temperature $\left[{ }^{\circ} \mathrm{C}\right]$, and

$\mathrm{T}_{\mathrm{S}}=$ temperature of storage tank at start of day $\left[{ }^{\circ} \mathrm{C}\right]$,

witb three coefficients, $\alpha_{0}, \alpha_{\mathrm{H}}$ and $\alpha_{\mathrm{T}}$. Storage is assumed well mixed at the start of the day. The relation is valid only for positive $Q$. A sample plot of test data is presented in Fig.1. It refers to one of three systems tested in different European Laboratoties during a Round Robin test programme (19861987), following the CSTG procedure.

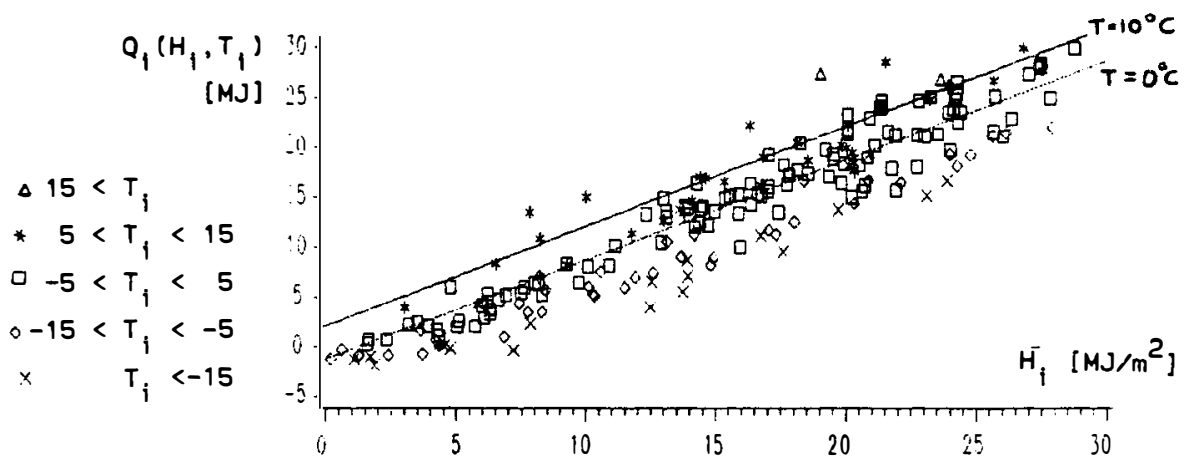

Fig.1 Input-Output Diagram for a DHW solar system (BP-Calpak).

The essential steps of the CSTG test procedure are the following:

1) Preconditioning: before the start of the all-day test, water at constant temperature $T_{c}$ is circulated through the system (with collector shielded from sun) until the entire system is at uniform temperature $\mathrm{T}_{\mathrm{s}}=\mathrm{T}_{\mathrm{c}}$.

2) Exposure: from 6:00 to 18:00 (solar time) the system is allowed to function normally, and the solar radiation $H$ during this period is recorded. The wind speed should not exceed the range of $3-8 \mathrm{~m} / \mathrm{s}$, and use of fans is recommended to maintain 3-5 m/s. No water is withdrawn during this time.

3) Draw-off: At 18:00 three tank volumes are withdrawn at constant flow rate of $0.600 \mathrm{~m}^{3} / \mathrm{h}$, while replenishing the tank with cold water at constant temperature $T_{c}$ (same as at start of day). The temperature $T_{\text {out }}$ during this withdrawl is monnitored, as function $T_{\text {out }}(V)$ of the withdrawn volume $V$. This temperature profile is called "draw-off temperature profile".

4) Loss coefficient of storage: The heat loss coefficient of the tank, $U_{S}$, is determined in a separate test by measuring the temperature decrease during the night after the tank has been filled with hot water.

\section{PRECDICTION OF LONG TERM PERFORMANCE}

\section{Day-by-Day Simulation}

The CSTG test procedure determines the parameters $\alpha_{0}, \alpha_{\mathrm{H}}$ and $\alpha_{\mathrm{T}}$ as well as $\mathrm{U}_{\mathrm{s}}$ and the draw-off profile $\boldsymbol{\gamma}$,

$$
\gamma=1-\int_{0}^{\mathrm{V}} \mathrm{d} Q / \mathrm{Q}_{\mathrm{o}}
$$

which is the energy remaining in the tank after extraction of a volume $V$ of water, with $\mathrm{Q}_{\mathrm{o}}=\mathrm{C}\left[\mathrm{T}_{\text {out }}(\mathrm{V}=0)-\mathrm{T}_{\mathrm{c}}\right]$ where $\mathrm{C}=\mathrm{V}_{\mathrm{s}} \rho \mathrm{c}_{\mathrm{p}} \quad\left(\mathrm{V}_{\mathrm{s}}\right.$-storage tank volume; $\rho$-water density; $\mathrm{c}_{\mathrm{p}}$-water specific heat). Assuming that the system does not change and that the operating conditions (load, insolation 
and ambient temperature) are known, one can predict the long term average performance of the system. We choose to state it in terms of $Q$, the long term average daily useful energy supplied by the system.

To calculate $Q$ we begin with the input-output relation for an arbitrary day $i$ :

$$
\mathrm{Q}_{\mathrm{i}}=\llbracket \alpha_{\mathrm{o}}+\alpha_{\mathrm{H}} \mathrm{H}_{\mathrm{i}}+\alpha_{\mathrm{T}}\left(\mathrm{T}_{\mathrm{a}, \mathrm{i}}-\mathrm{T}_{\mathrm{s}, \mathrm{i}}\right) \rrbracket_{+}
$$

where the subscript $i$ indicates that all quantities correspond to day $i$. Only positive values are counted, as indicated by the + subscript of the bracket; during days with negative values the system is not turned on and $Q_{i}$ vanishes.

The energy in storage is measured relative to the cold water temperature $T_{c, i}$; thus the storage starts the day with an energy content of $C\left(T_{s, i}-T_{c, i}\right)$. Adding $Q_{i}$ to the energy at the start of the day, one finds that the total energy in storage at the end of the day is

$$
\mathrm{Q}_{\mathrm{e}, \mathrm{i}}=\mathrm{C}\left(\mathrm{T}_{\mathrm{s}, \mathrm{i}}-\mathrm{T}_{\mathrm{c}, \mathrm{i}}\right)+\llbracket \alpha_{\mathrm{o}}+\alpha_{\mathrm{H}} \mathrm{H}_{\mathbf{i}}+\alpha_{\mathrm{T}}\left(\mathrm{T}_{\mathrm{a}, \mathrm{i}}-\mathrm{T}_{\mathrm{s}, \mathrm{i}}\right) \rrbracket_{+}
$$

A fraction $\left(1-\gamma_{i}\right)$ of $Q_{e, j}$ is withdrawn as useful energy, $Q_{\text {use, } i}=\left(1-\gamma_{i}\right) Q_{e, i}$. On days when the storage temperature stays entirely below $\mathrm{T}_{\text {load }}, \gamma_{\mathrm{i}}$ is equal to

$$
\gamma_{\min }=1-\int_{0}^{V_{1}} \mathrm{dQ} / \mathrm{Q}_{0}
$$

where $V_{1}$ is the volume extracted for the load. But when the temperature is higher, we assume the user to temper the overheated water with cold water to obtain the temperature $\mathrm{T}_{\text {load }}$ and we have

$$
\text { a) } \left.\gamma_{\mathrm{i}}=\operatorname{MAX}\left[\gamma_{\min },\left(1-\mathrm{Q}_{\text {load }, \mathrm{i}} / \mathrm{Q}_{\mathrm{e}, \mathrm{i}}\right)\right] \text { and } \mathrm{b}\right) \mathrm{Q}_{\mathrm{use}, \mathrm{i}}=\operatorname{MIN}\left[\left(1-\gamma_{\min }\right) \mathrm{Q}_{\mathrm{e}, \mathrm{i}}, \mathrm{Q}_{\mathrm{load}, \mathrm{i}}\right]
$$

$Q_{\text {load,i }}$ is given by $V_{1} \rho c_{p}\left(T_{l o a d}-T_{c, i}\right)$; load volume and temperature could also vary from day to day but here we have taken them as constant, for simplicity.

The heat loss from storage during the day is implicitly included in (3). To calculate the heat loss from storage during the night, we define $T_{e, i}$ as the average temperature of storage at the end of the day after the draw-off; it is given by

$$
\mathrm{T}_{\mathrm{e}, \mathrm{i}}=\mathrm{T}_{\mathrm{c}, \mathrm{i}}+\mathrm{Q}_{\mathrm{e}, \mathrm{i}} \gamma_{\mathrm{i}} / \mathrm{C}
$$

Since the heat loss is relatively small, one can approximate the time dependence of the storage temperature during the night by a straight line that decreases from $T_{e, i}$ to $T_{s, i+1}$. From the nocturnal energy balance equation, established with this assumption, we obtain

$$
\mathrm{T}_{\mathrm{s}, \mathrm{i}+1}=\mathrm{r}_{\mathrm{e}, \mathrm{i}}+(1-\mathrm{r}) \mathrm{T}_{\mathrm{a}, \mathrm{i}}^{\mathrm{i}} \text { with } \quad \mathrm{r}=\frac{\mathrm{C}-\mathrm{U}_{\mathrm{s}} \mathrm{t}_{\text {night }} / 2}{\mathrm{C}+\mathrm{U}_{\mathrm{s}} \mathrm{t}_{\text {night }} / 2}
$$

and $t_{\text {pight }}=$ duration of night [in s]; and

$\mathrm{T}_{\mathrm{a}, \mathrm{i}}=$ average temperature of the tank environment during the night following the $\mathrm{i}$ 'th day.

The recursion relation between $Q_{e, i}$ and $Q_{e, i+1}$ will be obtained taking (4) for day $i+1$ and substituting in it $\mathrm{T}_{\mathrm{s}, \mathrm{i}+1}$, given by (8), and $\mathrm{T}_{\mathbf{e}, \mathrm{i}}$, given by (7)

$$
\begin{gathered}
\mathrm{Q}_{\mathrm{e}, \mathrm{i}+1}=\mathrm{C}\left[\mathrm{r}\left(\mathrm{T}_{\mathrm{c}, \mathrm{i}}+\mathrm{Q}_{\mathrm{e}, \mathrm{i}} \gamma_{\mathrm{i}} / \mathrm{C}\right)+(1-\mathrm{r}) \mathrm{T}_{\mathrm{a}, \mathrm{i}}^{\prime}-\mathrm{T}_{\mathrm{c}, \mathrm{i}}\right]+ \\
+\llbracket \alpha_{0}+\alpha_{\mathrm{H}} \mathrm{H}_{\mathrm{i}+1}+\alpha_{\mathrm{T}}\left[\mathrm{T}_{\mathrm{a}, \mathrm{i}+1}-\mathrm{r}\left(\mathrm{T}_{\mathrm{c}, \mathrm{i}}+\mathrm{Q}_{\mathrm{e}, \mathrm{i}} \gamma_{\mathrm{i}} / \mathrm{C}\right)-(1-\mathrm{r}) \mathrm{T}_{\mathrm{a}, \mathrm{i}}^{\prime}\right] \rrbracket_{+}
\end{gathered}
$$

This is the basic equation for the calculation of long term system performance, to be used together with 
(6a) for $\gamma_{\mathrm{i}}$ and (6b) for $\mathrm{Q}_{\text {use, } \mathrm{i}}$. The long term system performance $\mathrm{Q}$ can be calculated numerically by evaluating these equations for a sequence of meteorological data, and averaging over the year.

Simple Correlation

The calculation would be simplified greatly if one had a correlation that would yield $Q$ directly in terms of average meteorological quantities. As a step in that direction we note that there are two thresholds in this problem. The turn-on threshold $\mathrm{H}$ - corresponds to the insolation at which the $\llbracket \rrbracket_{+}$in (3) vanishes. The second threshold $\mathrm{H}_{+}$is the value at which the insolation becames greater than necessary to satisfy the load. A solar water heater is most cost-effective if the climate is sunny and the collector area is not oversized. For that important case $\mathrm{H}_{\mathrm{i}}$ will rarely if ever fall outside the interval $\mathrm{H}$ to $\mathrm{H}_{+}$. Then threshold effects are neglegible, (9) is free of nonlinearities, and averaging it over a number $\mathrm{N}$ of days permits to replace $\mathrm{H}_{i}$ and $\mathrm{H}_{\mathrm{i}+1}$ by the average $\overline{\mathrm{H}}$, with analogous replacements for the other variables. The result is

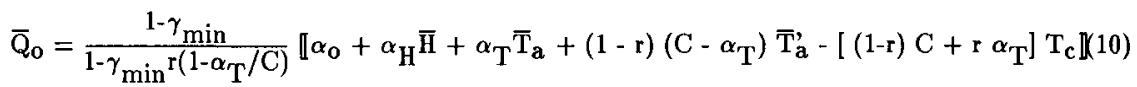

This solution could be corrected for thresholds if one develops correlations between the solar fraction $f$ (=ratio of $Q$ and annual average load $Q_{\text {load }}$ ) $=Q \backslash \bar{Q}_{\text {load }}$ and the variable $\bar{Q}_{0} \mid \bar{Q}_{\text {load }}$. The first approximation

$$
\mathrm{f} \tilde{=} 1-\exp \left(-\frac{\overline{\mathrm{Q}}_{\mathrm{o}}}{\overline{\mathrm{Q}}_{\text {load }}}\right)
$$

is already quite close to the exact result (maximum error about ten percent), and further corrections could be incorporated.

\section{INFLUENCE OF MEASUREMENT ERRORS OF I-O METHOD ON LTPP.}

Before discussing the predictive process of the method described above, a few comments must be made on the measurement errors associated with the I-O method itself. During 1986-87 three different solar systems where tested in different European Laboratories in a Round Robin test programme, folowing the CSTG test procedure. Five quantities were maesured during the test:

$$
\begin{aligned}
& \mathrm{H}=\text { daily irradiation on collector aperture (approx. } \pm 3 \%) ; \\
& \mathrm{T}_{\mathrm{a}}=\text { ambient temperature }( \pm 0.5 \mathrm{~K}) ; \\
& \mathrm{T}_{\mathrm{in}}=\text { temperature at inlet of storage }( \pm 0.1 \mathrm{~K}) ; \\
& \mathrm{T} \text { out = temperature at outlet of storage }( \pm 0.1 \mathrm{~K}) ; \text { and } \\
& \dot{\mathrm{V}}=\text { flow rate during draw-off }( \pm 1 \%) .
\end{aligned}
$$

The numbers in parentheses are the tolerances for the measurements as specified by CSTG (CSTG,1987), with which the tolerances reported by the individual laboratories are essentially in agreement. Based on an examination of the tolerances specified for the measurements, we have derived a priori estimates of the errors to be espected for the parameters of the linear I-O model. For a possible explanation of laboratory-to-laboratory differences of the results, we have distinguished random and systematic errors. While we find that the tolerances are, for most part, well chosen, two important sources of uncertainty remain: the determination of the effective ambient temperature $T_{a}$, and the difference $\left(\mathrm{T}_{\mathbf{s}}-\mathrm{T}_{\mathrm{e} 3 \mathrm{~V}}\right)$ between the storage temperature $\mathrm{T}_{\mathbf{S}}$ at the start of the test and the temperature $\mathrm{T}_{\mathrm{e} 3 \mathrm{~V}}$ of storage after withdrawing 3 tank volumes.

Assuming reasonably tight control of the uncertainties due to $T_{a}$ and $T_{c}$, The analysis of measurement errors indicates that the standard error $\sigma$ of the regression should be around $0.5 \mathrm{MJ}$ for the systems 
tested under the round robin program. But in reality the standard errors of the actual test results are about twice as large, as we found by carrying out a systematic regression analysis of the Round Robin test results. The explanation for the large errors appears to reside mostly in the uncertainties of $T_{a}$ and $\mathbf{T}_{\mathbf{c}}$, and to some extent in various and sundry little deviations from the CSTG procedure that usually pass unreported. Another part of the discrepancies may reside in shortcomings of the input-output model itself. Repeating the analysis with simulated test sequencies (Ernst et al.,1987) permits to conclude that a significant part of the scatter of the data arises from I-O model itself.

We are now in a position to conclude about the LTPP method and its application. In fact we have used the method of LTPP, which we state in terms of $Q$, as ultimate accuracy criterion for the testing method. Considering the day-by-day simulation we developed a procedure for translating the standard error $\sigma$ of the regression into the standard error $\sigma_{\mathrm{Q}}$ of $\mathrm{Q}$. The latter depends on the utilization scenario, in particular on the climate. In absolute terms $\sigma_{Q}$ for a given test sequence and load scenario is roughly the same for a cloudy climate (Uccle, $\overline{\mathbf{K}}_{\mathrm{T}}=.36$ ) and for a sunny climate (Carpentras, $\left.\overline{\mathrm{K}}_{\mathrm{T}}=.55\right)$; the relative error for the cloudy climate is about twice that for the sunny climate.

Most Round Robin sequences, if taken alone, appear to yield acceptable precision for the LTPP, with a standard error $\sigma_{\mathrm{Q}}$ below $0.3 \mathrm{MJ}$. But differences between different sequences, especially from different laboratories, are much larger, with $\sigma_{\mathrm{Q}}$ on the order of $1 \mathrm{MJ}$ (relative error around $5 \%$ in sunny, $10 \%$ in cloudy climates) or even more in some cases. Thus the precision of a single sequence cannot be trusted as long as one does not exercise tighter control over systematic errors. These could be reduced to perhaps half by tightening certain aspects of the test procedure, i.e., the constancy of the cold water supply and the ventilation of the collector.

The accuracy of the results depends not only on the accuracy of the measurements, but also on the meteorological conditions and the duration of the test. The precise relationship between $\sigma_{Q}$ and the test conditions is not very transparent, involving as it does a day-by-day simulation. As an alternative we have derived an approximate formula that shows the relationship in simple closed form. The number of test days, required to obtain a specified accuracy, depends very much on the range of insolation and temperature values during the test. Typically a range of ten to fifty days will suffice. Since the actual test conditions cannot be foressen, it is not advisable to impose a fixed upper limit for the test duration. Instead, to minimize the duration, we urge that the error $\sigma_{O}$ be evaluated automatically at the end of each test day. This could be done for several typical operating conditions. The necesary calculations take less than a minute on a personal computer, and can easily be incorporated in the software of the data acquisition system.

As for the simple correlation for $\bar{Q}$ it was found that it yielded good results as long as $\mathrm{H}_{i}$ stayed within the thresholds, $\mathrm{H}$ - and $\mathrm{H}_{+}$, i.e. in most well designed systems in actual DHW situations.

\section{REFERENCES}

CSTG, 1987. European Solar Collector and Testing Group. Proceedings 7th Meeting, Catania, Italy, 14 Dec. 1987, Edited by E.Aranovitch, D.Gilliaet, W.B.Gillet and J.E.Bates. Report EUR 11604 EN, Joint Research Center, Ispra, Italy.

Ernst,M.;Kiibler,R.;Fisch,N.;Hahne,E. 1988."SDHW system testing”. Report of the Institut fiir Thermodynamik und Wärmetechnik, Universität Stuttgart.

Bourges,B.;Rabl,A.;Leide,B.;Carvalho,M.J.;Collares-Pereira,M. 1989. " "Solar Water Heater Tests: Measurement Errors and Consequences". Final Report of Contract n.3334-12-87 ED ISP P between DER-LNETI (Portugal), École des Mines, Paris, France and J.R.C., Ispra, Italy, submited to Solar Energy 